\title{
Corporate governance and intellectual capital disclosure: evidence from the Scandinavian countries
}

\section{Belle Selene Xia* and Ignace De Beelde}

Department of Accounting and Corporate Finance, Ghent University, Belgium

Email: belleselene.xia@ugent.be

Email: ignace.debeelde@ugent.be

${ }^{*}$ Corresponding author

\author{
AQ1: Please supply \\ zip code for the country
}

\begin{abstract}
In the modern society intellectual capital (IC) disclosure offers valuable insights on the information transparency between the organisation and its stakeholders. The purpose of the present study is to analyse the determinants of IC disclosure based on the firm data collected from the Scandinavian countries. We have chosen to analyse 123 annual reports in the local language for the period of 2008 to 2012. The annual reports act as one of the best sources of data revealing important information about firms that are beyond the reporting requirements of the accounting regulations. This paper combines the empirical research of IC disclosure with the previous literature to identify its strategic implications on corporate governance. The aim is to examine the relationship between firm size, leverage ratio, information asymmetry and industry-specific factors on the level of IC disclosure. Our results call the potential need for more IC disclosure.
\end{abstract}

Keywords: intellectual capital reporting; organisational learning; intangible resources; competitive strategy.

Reference to this paper should be made as follows: Xia, B.S. and De Beelde, I. (xxxx) 'Corporate governance and intellectual capital disclosure: evidence from the Scandinavian countries', Int. J. Learning and Intellectual Capital, Vol. x, No. $\mathrm{X}, \mathrm{pp} . \mathrm{Xxx}-\mathrm{xxx}$.

Biographical notes: Belle Selene Xia is a Distinguished Researcher in the Department of Accounting and Corporate Finance at the University of Ghent, Belgium. Her education includes a Bachelor of Science and Technology in Computer Science from the Helsinki University of Technology and a Master of Science and Technology from the same university. She has collected a wide range of international working and consulting experiences from companies such as Nokia Siemens Networks, HiQ International, Helsinki Op Bank, Euroclear plc, Asahi Kasei Corporation and Louis Vuitton. Her current research concentrates on the profit maximisation strategies of the listed companies and the strategic management of financial reporting.

Ignace De Beelde is affiliated as the Full Professor at Ghent University. He has been appointed Department Chair of the Department of Accounting, Corporate Finance and Taxation of the Faculty of Economics and Business Administration. $\mathrm{He}$ is also the Vice-Dean responsible for education at the Faculty of Economics and Business Administration. He has acted as a Visiting Professor at HEC Paris, Grenoble, Ecole de Management and Skema Business School. His main research interests include various aspects of auditing, the development of financial reporting and corporate social reporting. He Chairs the Audit Committee of the Flemish Parliament. 
This paper is a revised and expanded version of a paper entitled [title] presented at 17th Annual Conference on Finance and Accounting (ACFA 2016), University of Economics, Prague, May, 2016.

AQ2: Please supply

title and date of the conference.

\section{Introduction}

The Scandinavian governments recognise the vital importance of sound corporate governance on the well-functioning of the financial market, and thus have taken active measures to constantly develop their accounting standards and regulations (Knudsen et al., 2015). The aim is to invite more quality disclosure and improved management practices from the publicly listed companies. Consequently, the Scandinavian countries, particularly Denmark, Norway, Sweden and Finland, have been increasingly at the centre of research attention in terms of their welfare states as well as their corporate governance characteristics (Gray et al., 2004). Given the scarce research done on the corporate disclosure of intellectual capital among the Scandinavian firms, the need to do so is strong. Consequently, this paper will examine the intellectual capital (IC) disclosure of the listed firms in the Scandinavian countries as well as its strategic implications on corporate governance.

The role of intellectual capital played in corporate governance is gaining a rising attention, as high financial assets are tied to intangible assets (Muttakin et al., 2015). Firms have recognised this trend via an increasing amount of investment in intellectual capital and intangible assets. Consequently, research in the subject matter would deepen our understanding on the role of intellectual capital played in corporate governance. Empirical research on the disclosure of intellectual capital including its causes and implications derives high potential and would be useful in understanding how firms use its intangible assets to attain a competitive advantage in the market. While accounting standards and regulations currently require a relatively low level of intellectual capital disclosure in firms' annual reports, firms choose to voluntarily disclose information related to their intangible assets in accordance to their strategic needs and industry norms (Manolopoulou and Tzelepis, 2014). In other words, the freedom to decide on the level, as well as the quality of IC disclosure, can be properly managed, and thus deserves analysis on its own.

Firms disclose information related to their intangible assets in accordance with their business culture and as a part of their branding strategy (Gan et al., 2013). In addition to the corporate disclosure regulated by the accounting standards, there are various management incentives behind intellectual capital disclosure. These management incentives can be analysed via an empirical study and are dependent on the industry type. For example, in R\&D-intensive industries, the management of intellectual capital offers firms a competitive advantage by which they can compete against other players in the market (Xia, 2015). Intellectual capital disclosure can also be used to attract financial advantages, such as additional shares in the capital markets. Consequently, the incentives behind intellectual capital disclosure may vary resulting in a varying degree of IC disclosure as well as differences in the quality of disclosure. Despite the importance of the subject, research in intellectual capital disclosure along with the management incentives to disclose IC information remains scarce (Brüggen et al., 2009). 
The innovative feature of this paper is to examine a combination of different firmspecific factors, such as firm size, the leverage ratio and information asymmetry, as well as industry groupings, on the level of IC disclosure based on the firm data collected from the Scandinavian countries. This information is excavated from the annual reports, which act as one of the best sources to examine the level of corporate disclosure. This is because firm's annual reports reveal valuable information about their business practices that are beyond the reporting requirements of the accounting regulations. Consequently, the research questions of the present study are formulated as below:

1 Does the type of industry acts as a determinant behind the disclosure of intellectual capital?

2 Is the level of IC disclosure affected by firm-specific factors, such as firm size, the leverage ratio and information asymmetry?

The goal of this research is to deepen our understanding of corporate governance and the IC disclosure practices of the listed firms in the Scandinavian countries. We have organised our paper as follows. First, we will review the traditional literature and the importance of the research topic. Then, we will elaborate the data and research design of this study to be confirmed by empirical data. Thereafter, we will discuss how do our results contribute to the advancement of the field including their strategic implications on corporate governance and their policy impacts on the accounting regulations in the last section of this paper.

\section{Literature review (intellectual capital disclosure)}

\subsection{The importance of intellectual capital disclosure on corporate decisions}

In today's society, firm's competitive advantage is no longer built solely on production. Previous research has shown that the management of intellectual capital creates enterprise value especially for firms operating in the R\&D intensive industries (Verbano and Crema, 2016). Researchers such as Petty and Guthrie (2000) have aligned the development of our society in the information age to the role played by intellectual capital in the corporate life. Along with the economic, technological and sociological developments, intellectual capital acts as a motor that drives innovation in a knowledgebased economy. In the business context, the sound management of intellectual capital is one of the key determinants behind the creation of organisational value (Chou, 2016).

Intellectual capital manifests itself as important strategic assets for a firm in terms of its growth and innovation. By intellectual capital disclosure, it refers to the disclosure of strategic and operative information of the firms' intangible assets. That is, the disclosure of intellectual capital reveals essential information about a firm's knowledge-based resources and the value that they contribute to the firm's performances. Intellectual capital can be divided into human, organisational and relational capital (Ienciu, 2014). Human capital includes both tacit and explicit knowledge of the employees as well their competencies and skills to perform tasks. Organisational capital includes technological innovations, corporate culture, intellectual property and business processes of a firm. Relational capital is then reflected in the quality of relationships of the firm with its stakeholders including but not limited to its customers, suppliers, shareholders and investors. Therefore, intellectual capital disclosure reveals crucial information about the 
key capabilities and strategic resources of a firm and provides one of the most important sources of information required for making strategic and operative decisions concerning a firm's intangible assets (Dumay et al., 2015). The definition of intellectual capital and its taxonomy discussed here also allows us to measure its components in a systematic manner.

Currently, the lack of clear guidelines in financial reporting regarding intellectual capital contributes to the difficulty to standardise the level of disclosure on intangible assets in the annual reports. Consequently, the level of IC disclosure not only varies across firms but also across industries. Nevertheless, it is acknowledged that the stringent regulations on IC disclosure would make it inappropriate due to the various firm characteristics and industries in which the firms are operating in. From the strategic management point of view, when firms are given the freedom to disclose information on intellectual capital, how they choose to disclose this information offers valuable insights on the corporate identities of these firms (Guthrie and Petty, 2000).

Intellectual capital disclosure reveals strategic information on the financial position as well as the competitiveness of the firm. From the investors' point of view, IC disclosure would give them the essential information to evaluate the value and the financial prospect of the firm in the long run. From the company's point of view, firms disclose corporate information in order to enhance their reputation and as means to build trust with the stakeholders. This trust is of vital importance and has strategic implications, which in return helps the firms to sustain a competitive advantage. The voluntary disclosure of intellectual capital in the annual reports also prevents false information from spreading to the public, and thus the level and the quality of IC disclosure is continuously managed as part of a company's brand and would necessitate further research (Melloni, 2015).

\subsection{Research issues in intellectual capital disclosure}

Shareholders and public investors would be one of the primary groups who benefit the most from intellectual capital disclosure. Hope (2003) has confirmed via a firm sample collected from 22 countries that voluntary corporate disclosure provides valuable insights also to the analysts and other stakeholders who use this information in their decisionmaking process. From the marketing and communication point of view, firms who choose to disclose information about intellectual capital would appear to be more socially responsible. Consequently, the degree of corporate social responsibility in a firm's business operations can be examined via the level and the quality of information disclosed in its annual reports (Dias et al., 2016). However, ways to measure intellectual capital disclosure are admitted to be difficult. Research models aimed to measure the level of IC disclosure by segregating the firm characteristics with that of the industry groupings offers one way to overcome this challenge. In the present study, the effect of both firm-specific attributes and industry groupings will be examined on the level of IC disclosure using the research framework established by the previous literature.

In order to capture the value generated by the intellectual capital disclosure, both researchers and practitioners have used various research models, such as the intellectual capital disclosure index, to quantify the level of IC disclosure. However, as there exist no clear accounting regulations on IC disclosure, it is difficult to objectively measure the quality of IC disclosure from the annual reports. Nevertheless, researchers, such as Guthrie and Petty (2000), have confirmed the importance of annual reporting of intellectual capital and intangible assets, and thus the annual reports do offer us some 
useful information, which can be used to study the relationship between corporate governance attributes and the level of IC disclosure. Previous research has established that the concept of intellectual capital is rather misunderstood due to a lack of research and the need for further research is strong (Dumay, 2016). Consequently, in the present study, the aim is to contribute to the advancement of the field and further our understanding of the IC disclosure literature using a set of firm data collected from the Scandinavian countries. Subsequently, the hypotheses of the present study are formulated as below:

H1: Firms operating in industries that put more emphasis on intangible assets exhibit a higher level of intellectual capital disclosure.

Hla: Firms operating in the IT industry exhibit a higher level of intellectual capital disclosure.

H2: Disclosure in intellectual capital is more related to industry-specific factors rather than firm-specific factors.

H2a: The level of intellectual capital disclosure is not affected by firm size.

$H 2 b$ : The level of intellectual capital disclosure is not affected by the leverage ratio.

H2c: The level of intellectual capital disclosure is not affected by information asymmetry.

Brüggen et al. (2009) have studied a data sample of 125 publicly listed firms and combined an analysis of those industries in which rely their business heavily on R\&D and the value bought by the firm's intangible assets. In line with the public expectation from the investors and the stakeholders, the authors have found that firms choose to disclose information based on the corporate culture and the macro-environment in which they are operating in. The determinants of intellectual capital disclosure include the industry type and firm size. In the present study, we have chosen to look at the effect of industry type, firm size, the leverage ratio and information asymmetry on the level of IC disclosure. Our results confirm the correlation between the level of IC disclosure and the industryspecific factors.

The research framework established by Brüggen et al. (2009) has been previously adopted in various disclosure studies including but not limited to Guthrie and Petty (2000), Brennan (2001), Bozzolan et al. (2003), April et al. (2003), Goh and Lim (2004), Abeysekera and Guthrie (2005) and Xia and De Beelde (2016). These studies have aimed to examine the level of disclosure based on the outcome of the content analysis on a sample of listed firms. While these papers have studied a relatively small number of sample firms, such as 19 listed companies in Guthrie and Petty (2000)'s research and 11 listed companies in Brennan (2001)'s research, the disclosure theories established in these papers derives high significance and invite further research on IC disclosure. Specifically, Brüggen et al. (2009) have conducted a content analysis on the disclosure items followed by a regression analysis in order to examine the research question. In their studies, the disclosure items were determined based on the previous literature and thereafter aggregated in order to quantify the frequencies of their occurrence. In this paper, we will further explore this type of research design to study the corporate governance practices and the related IC disclosure activities in the Scandinavian contexts. 


\section{Research methodology}

For each of the firm in the given sample, we have chosen to analyse the annual reports for the three consecutive years as our primary source of data. First, we will employ content analysis to examine the intellectual capital reporting practices of these firms. Then, we will conduct regression analysis to evaluate the relationship between the firm and the industry-specific factors on the level of IC disclosure. In this case, the level of IC disclosure is measured by a list of items that can be classified into the following categories:

1 human capital, which reveals information related to the firm from the employees' point of view

2 organisational asset, which acts as the management backbone and is perceived as the organisational structure of the company

3 environmental capital, which bonds the firm with its external macro-environment.

\subsection{Dependent variable}

Table 1 shows the determinants of IC disclosure that are used in this study based on the previous literature (Brüggen et al., 2009). Based on the information collected from the annual report, the patterns of these textual data can be captured to further our understanding of the IC disclosure literature from an empirical point of view. It is acknowledged that the result of the content analysis is context-dependent and that this process also invites selection bias. While the unique nature of the individual text cannot be pervasively generalised as a result of the qualitative study, content analysis can be useful as a method to study the underlying construction of the textual data. Specifically, we have chosen to use inductive content analysis to aggregate the determinants of intellectual capital disclosure in accordance with the previous literature.

Table 1 The determinants of intellectual capital disclosure

\begin{tabular}{llll}
\hline Intellectual property & Human capital & Organisational asset & Environmental capital \\
\hline Economic value added & Employee expertise & Cultural diversity & Supplier knowledge \\
Intellectual capital & Employee skill & Organisational culture & Supply chain management \\
Knowledge asset & $\begin{array}{l}\text { Employee } \\
\text { productivity }\end{array}$ & Corporate learning & Customer knowledge \\
Intellectual resources & Employee know-how & Knowledge sharing & Company reputation \\
Knowledge value & Human asset & Organisational learning & Company brand \\
Intellectual property & Human resources & Knowledge management Environmental asset \\
Intellectual know-how & Human value & Information system & Customer relationship \\
& & & management \\
Business intelligence & Expert team & Value network & Goodwill \\
\hline
\end{tabular}




\subsection{Independent variables}

For the independent variables, the firm size is measured by the natural logarithm of the total assets; the leverage ratio is calculated by the debt-to-equity ratio, and information asymmetry is indicated by the percentage of stock not held by the 20 largest shareholders based on the information provided in the annual reports. These variables are included in the subsequent regression model. It is expected that investors might be more concerned with the intellectual capital disclosure in cases where investment is mostly based on the firm's intangible assets, and this should be reflected in the industry coefficients of our model.

\subsection{Data collection}

Our data consists of the listed firms in the Scandinavian countries. Table 2 shows the industries in which these firms operate. From each industry, we have collected the annual reports of these firms from the years 2008, 2010 and 2012. This gives us a total sample of 123 annual reports under study. The annual reports act as one of the best sources of IC disclosure. This is because they reveal strategic information about the firms that are beyond the reporting requirements of the accounting regulations.

Table 2 Sample firms classified by industries

\begin{tabular}{lcc}
\hline Industry type & Number of firms & Percentage \\
\hline Energy & 5 & 12.20 \\
Information technology & 6 & 14.63 \\
Consumer goods and services & 5 & 12.20 \\
Basic industry & 5 & 12.20 \\
Groceries & 3 & 7.32 \\
Finance & 6 & 14.63 \\
Industrial products and services & 10 & 24.39 \\
Healthcare & 1 & 2.44 \\
In total & $41(N=123$ in total $)$ & 100 \\
\hline
\end{tabular}

We have used the Industry Classification Standard in Finland as the guideline to group these sample firms. As shown in Table 1, the 123 annual reports are collected from the following industries: energy (5 companies), information technology (6 companies), consumer goods and services (5 companies), 1 basic industry (5 companies), groceries ( 3 companies), finance (6 companies), industrial products and services (10 companies) and healthcare (1 company). In this case, the basic industry refers to the industrial sector, which exports all or nearly all its production. In order to increase the reliability of our results, firms are randomly chosen and fairly well represent the industry structure in the Scandinavian countries. 


\subsection{Methods}

An ordinary least square (OLS) regression model is constructed to analyse the firm- and industry-specific factors on the level of IC disclosure. In the subsequent regression analysis, we have focused our analysis based on the information provided in the annual reports from the year 2008. We have found similar results when analysing data from 2010 and 2012, and thus we do not present the comparison in this paper. Specifically, our OLS regression model is formulated as follows:

$$
\begin{aligned}
\text { Disclosure of Intellectual Capital } & =\beta_{0}+\beta_{1} \text { Size }+\beta_{2} \text { Leverage } \\
& +\beta_{3} \text { Information Asymmetry }+\beta_{4} \text { IT Industry } \\
& +\beta_{5} \text { Basic Industry }+\beta_{6} \text { Energy Industry }+\varepsilon
\end{aligned}
$$

where the intellectual capital disclosure is the measure of the level of IC disclosure from the annual reports, as specified in Table 3. The coefficients from $\beta_{4}$ to $\beta_{6}$ are the coefficients of dummy variables for the industries analysed in our given sample, as specified in Table 2. Each dummy variable takes the value of 1 for each industry respectively and 0 otherwise. The indicators corresponding to the other industries have been removed to alleviate collinearity, while at the same time allowing an analysis of hypothesis $\mathrm{H} 1$ by including industries with different levels of intangible assets.

Table 3 The number of disclosed determinants of intellectual capital

\begin{tabular}{lrrr}
\hline Groups of determinants & 2008 & 2010 & 2012 \\
\hline Intellectual property & 88 & 70 & 88 \\
Human capital & 106 & 105 & 100 \\
Organisational asset & 17 & 25 & 20 \\
Environmental capital & 1026 & 1201 & 1082 \\
Total & 1237 & 1401 & 1290 \\
\hline
\end{tabular}

In order to examine the robustness of our results in a setting with a reduced statistical variance, we have formulated a second OLS model by excluding the field variables from Model (1). As the field variables are removed, the reduced model addresses Hypothesis $\mathrm{H} 2$ specified in our study. Therefore, the regression equation is formulated as below:

$$
\begin{aligned}
\text { Disclosure of Intellectual Capital }= & \beta_{0}+\beta_{1} \text { Size }+\beta_{2} \text { Leverage } \\
& +\beta_{3} \text { Information Asymmetry }+\varepsilon,
\end{aligned}
$$

where the variables are specified in accordance with the previous regression model. In order to assess the effect of collinearity, we have performed a factor analysis of the independent variables specified in Model (1). The results are shown in Table 4.

Table 4 Factor analysis of the independent variables in the OLS regression model (1)

\begin{tabular}{lcccccc}
\hline Component & 1 & 2 & 3 & 4 & 5 & 6 \\
\hline$\%$ of variance & 26.56 & 25.76 & 18.36 & 12.64 & 10.83 & 5.81 \\
Cumulative \% of & 26.56 & 52.36 & 70.72 & 83.35 & 94.19 & 100 \\
variance & & & & & & \\
\hline
\end{tabular}


In addition to the classical standard errors of the regression coefficients, we have also estimated the heteroscedasticity robust standard errors as explained in the work of White (1980). Moreover, the p-value of the complete model is computed using the Wald test; for analysis purposes, the heteroscedasticity robust estimates will take priority, as there are no specific reasons to assume homoscedasticity of the noise terms in Models (1) and (2).

\section{Results}

It is confirmed that based on the extent of IC disclosure appeared in the annual reports, firms in the Scandinavian countries put high significance on the management of intellectual capital. Accounting and reporting regulations also require that intellectual capital and intangible assets related to patents, trademarks and copyrights to be disclosed in the annual reports, which partially explains the relatively high level of IC disclosure of these firms. Moreover, as a corporate strategy to build a strong brand and to combat the drawbacks associated with information asymmetry, the disclosure of intellectual capital reveals valuable insights about the business culture and the corporate identities of these firms. During the content analysis process, IC disclosure is found to be one of the most frequently disclosed items in the notes of financial statement, management forecasts and operation reports. This confirms the fact that the top management does put a strong emphasis on intellectual capital reporting and that there is a growing interest in the subject matter especially for firms operating in the R\&D intensive industries.

\subsection{Descriptive statistics}

Table 3 shows the frequency of the determinants of the IC disclosure. These frequencies are estimated as approximations where annual reports are collected in the local language. We have aimed to increase the reliability of our results via random selection. Moreover, the results of the content analysis are compared with the results of similar studies from the previous literature. Consequently, it is seen that firms tend to disclose less information on their business organisations and more on their relationships with the outside environment. Table 3 also shows that the level of IC disclosure is more dependent on the pre-grouped categories rather than the specific year of disclosure. Moreover, despite the five-year period differences at the time of measurement, firms seem to exhibit a rather similar tendency to disclose information on intellectual capital and that the tendency of increasing disclosure from year to year is unclear. This result implies that firms' corporate identity is slow to change and that there exists a high potential for more disclosure of information on intellectual capital and intangible assets.

Table 5 shows the descriptive statistics for the variables in Model (1) including the industry indicator variables in Table 2 . From Table 5, we see that there are no significant outliers in the data in terms of extreme values. To account for collinearity, we have performed a factor analysis of the independent variables in Table 4. It is seen that the last component displays a relatively small share of the variance; however, as it turns out our regression results are statistically significant, and thus the slight collinearity does not pose a significant problem for our subsequent analysis. 
Table 5 Descriptive statistics

\begin{tabular}{lrccc}
\hline & Mean & Std. dev. & Minimum & Maximum \\
\hline Disclosure & 30.17 & 24.29 & 0 & 96.00 \\
Log firm size & 21.60 & 2.34 & 16.42 & 25.82 \\
Leverage & 0.60 & 0.15 & 0.31 & 0.97 \\
Inf. Asym. & 49.39 & 21.05 & 0 & 97.91 \\
\hline
\end{tabular}

Table 4 shows the results of a factor analysis of the independent variables presented in Table 5. The aim of the factor analysis is to more closely assess the presence of collinearity. A factor analysis is performed in this case to capture the variability among the observed and the correlated variables via a number of factors. This knowledge reveals the interdependence relationships between the observed variables in the dataset. Therefore, Table 4 displays the proportionate variances of the factors to the total variance under analysis. While it is acknowledged that the last components may demonstrate less variance in value respectively, collinearity is shown to be relatively modest to support our subsequent OLS analysis.

\subsection{Multiple linear regression analysis}

The results of OLS regression with Model (1) are summarised in the first column in Table 6. In this table, the standard statistics, as well as the heteroscedasticity-consistent standard errors and the Wald test, are computed to our models. These tests are performed to assess whether there exists any heteroscedasticity in our sample data. Consequently, when it comes to the heteroscedasticity-consistent estimates, which should take priority as homoscedasticity has not been verified, Model (1) is seen as statistically significant. The statistically significant coefficient, in this case, is the IT industry.

Table 6 OLS regression on the disclosure of intellectual capital with classical and White's heteroscedasticity robust standard errors (the latter on the right side) in parentheses

\begin{tabular}{lcc}
\hline Independent variable & Model 1 & Model 2 \\
\hline Constant & $-29.37(41.42 / 35.45)$ & $-10.20(42.63 / 41.53)$ \\
Log Size & $1.61(2.38 / 2.42)$ & $1.25(2.50 / 2.98)$ \\
Leverage & $27.09(31.36 / 32.69)$ & $12.86(32.52 / 37.30)$ \\
Information asymmetry & $0.11(0.25 / 0.23)$ & $0.13(0.25 / 0.24)$ \\
IT industry & $24.47(11.10 / 10.38) * *$ & \\
Basic industry & $-7.18(12.50 / 6.47)$ & \\
Energy industry & $6.39(17.55 / 11.98)$ & $0.06(0.34)$ \\
$R^{2}$ and p-value of the model & $0.25(0.03)$ & \\
\hline
\end{tabular}

The $p$-values of the models were computed as the Wald test using the heteroscedasticity robust weight covariance estimate. Statistically significant (on the 0.05 confidence level) coefficients are marked by $* *$.

Based on the regression results, the logarithmic firm size and the leverage ratio do not have a strong influence on the level of IC disclosure. This can be partially explained by 
the fact that IC disclosure differs from corporate disclosure, as disclosure on intellectual capital is more related to industry-specific factors rather than firm-specific factors. In other words, irrespective of the firm size and leverage ratio, management has the incentives to disclose information on intellectual capital based on public expectation, which are not reflected in these firm characteristics. As a matter of fact, the results of the regression model show that the statistically significant coefficient corresponds to the ITindustry, partially confirming Hypothesis 1. In Model (2), we have simplified our analysis in order to examine the role of information asymmetry on the level of IC disclosure more in detail. In this case, we have decided to remove the field indicators in order to reduce the estimation variance. The results of the OLS estimation of Model (2) are summarised in Table 6.

The results from the Model (2) show that information asymmetry does not play a significant role on the level of intellectual capital disclosure. This result is also confirmed by previous literature (Brüggen et al., 2009). This is partially due to the fact that information asymmetry alone does not affect the management's decision to disclose information but that its potential value is maximised as a result of the disclosure. Nevertheless, it is acknowledged that one potential research issue with the empirical analyses is the potential limitation regarding the sample size. Therefore, in this case, the finding may not reveal the 'true' relationship between information asymmetry and the level of IC disclosure. Nevertheless, this is acknowledged to be of a concern in all empirical studies. Our goal here is not to establish a stringent causality relationship between these contextual factors and the level of IC disclosure but to capture potential trends and patterns.

\section{Conclusions}

Intellectual capital being part of organisational value creation is manifested through the close linkage between the different internal and external organisational resources. Within the context of intellectual capital, a firm's performance can be evaluated from the stakeholders' point of view suggesting that firm performance is built on top of the relationships that it establishes with its stakeholders, such as the relationship with its shareholders, investors, employees, customers, suppliers and the government (Lins et al., 2017). Therefore, value creation is generated from firms gaining a competitive advantage resulting in their sound financial performances via acquiring and effectively managing its strategic assets (Xia, 2016). As intangible assets are defined by the previous literature to be valuable, rare, non-substitutable and hard to imitate, intellectual capital incorporates intangible value, which confirms its potential and significance for firms to use them in achieving superior performance. Intellectual capital disclosure also enhances a firm's brand and reputation.

A firm's organisational performance is admittedly to be heavily influenced by its intangible assets and knowledge management. These human, organisational and relational capital assets can be used to create value to the organisation especially in industries where the technological know-how offers a firm its competitive advantage. However, the concept of intellectual capital is rather complex, and until now, it has not been fully understood by most of the organisations (Khan, 2015). Therefore, there is a vital need for more research in IC disclosures. As a matter of fact, without proper IC 
evaluation and treatment, having a quality financial report may be arguably difficult if not impossible.

Previous research has established that intellectual capital can be categorised and that the level and the quality of IC disclosure vary across firms and firms from different industries (Maaloul and Zéghal, 2015). The present study differs from the previous studies in terms of the time, data sample, industry type and other contextual factors constructed in the current research paradigm. Previous research has shown that the studies of corporate disclosure is geographically bounded and may not be extended across national borders due to the different regulatory and economic environments in which these firms are operating in Kang et al. (2007). Consequently, we have chosen to limit our research focus on IC disclosures in the Scandinavian countries. Based on the results there exist industry-specific factors that are found to contribute to the level of IC disclosure in line with the previous literature. However, when it comes to the firmspecific factors, such as firm size, the leverage ratio and information asymmetry, the level of IC disclosure seems to exhibit a much weaker correlation. This can be partially explained by the fact that while the public would benefit from the intellectual capital disclosure, the top management may be refrained from disclosing strategic information to their competitors irrespective of their firm structures and as a result of insider trading and management opportunism. Nevertheless, intellectual capital disclosure is an integrated part of corporate governance, and thus can be effectively managed to enhance a firm's corporate and social identity.

\section{Limitations of the study and future research}

The present study reports on the IC disclosure activities in the Scandinavian contexts, as there is an increasing demand to evaluate the top management practices of these firms to update and further our understanding in the IC disclosure literature. Based on the results, there is room for more research on the relationship between the firm-specific factors and the level of IC disclosure elsewhere. This is because the research of IC disclosure is often limited to the information provided in the local data, while the generalisability of such findings may not be extended across national borders due to the different regulatory and economic environments as well as the size of capital markets in these regions. Consequently, the importance and the value of IC disclosure should be considered to be separately examined in different regions. Moreover, we have chosen a cross-sectional analysis to discover the relevance of findings across industries. Alternatively, it would be interesting to limit the research focus to one specific industry in order to capture any possible trends in the IC disclosure in the respective industry.

While we have aimed to examine the relationship between the firm-specific factors and industry groupings on the level of IC disclosure, this type of measurement framework of IC disclosure is admittedly not perfect. Therefore, there exist future research opportunities to consider the introduction of other control variables in order to examine the significance of IC disclosure and its strategic implications on corporate governance. Moreover, we have collected data over a five-year period, which allowed us to capture some potential trends in the IC disclosure practices. However, it is possible that the relationship between the IC disclosures and the different organisational factors may be closely related in the recent years, and thus would show more variations under a different research framework. Consequently, the findings of this paper are not aimed to show a 
strict causality relationship between these influential factors but aimed more at capturing possible patterns in how IC disclosure is executed in the Scandinavian context.

In line with the previous literature, the industry type seems to affect the level of IC disclosure especially those industries which heavily rely their business on the value brought by the firm's intangible assets. Under the public pressure from the investors and other stakeholders, management chooses to disclose information in accordance to the industry norms, and intellectual capital disclosure is found to have enterprise values to these firms in the long run. This also partially explains why firms exhibit similar behaviour on the disclosure practices from year to year and that the significance of IC disclosure remains high. Given that the level of IC disclosure is related to the industry in which the firm is operating in, even in the absence of compulsory accounting regulations for IC disclosure, firms would choose to disclose information rather consistently of what is expected of them and depending on the nature of their business. Therefore, in terms of future research, it would be interesting to integrate the expectation theory into the intellectual capital disclosure literature and evaluate the link between public expectation and the level of IC disclosure.

The accounting rules and policies announced by the Scandinavian governments, especially regarding the accounting standards governing the ownership structures and board compositions, would affect the level and the quality of corporate disclosure. The Scandinavian firms are globally recognised for their sound corporate governance and disclosure practices (Thomsen, 2015). This is partially due to the fact that the Scandinavians firms have managed to integrate the corporate responsibility and stakeholder support in their daily operations, which result in their good reputation. In other words, the concept of 'creating shared value' for firms in the Scandinavian countries is reflected by the fact that they place high importance on sound corporate governance and sustainable performances in their management philosophy (Strand et al., 2015). This paper has further reinforced this theory via an empirical study of the different corporate governance attributes and industry groupings on the level of IC disclosure. While this paper has focused on the Scandinavian context, the findings presented in this paper offer some interesting insights for international academics who may use our results as a basis for further research.

\section{Acknowledgement}

We are extremely grateful for the valuable feedback and contribution of Professor Heidi Vander Bauwhede, Professor Philippe Van Cauwenberge, Professor Mirjam Knockaert and Dr. Elia Liitiäinen. The authors would also like to express sincere gratitude to the honourable Editor-in-Chief, Prof. Patricia Ordóñez de Pablos, the Associate Editor and the two anonymous reviewers whose suggestions have resulted in major improvements in this paper. Any remaining errors are entirely our responsibility.

\section{References}

Abeysekera, I. and Guthrie, J. (2005) 'An empirical investigation of annual reporting trends of intellectual capital in Sri Lanka', Critical Perspectives on Accounting, Vol. 16, No. 3, pp.151-63. 
April, K.A., Bosma, P. and Deglon, D.A. (2003) 'IC measurement and reporting: establishing a practice in SA mining', Journal of Intellectual Capital, Vol. 4, No. 2, pp.165-80.

Bozzolan, S., Favotto, F. and Ricerri, F. (2003) 'Italian annual intellectual capital disclosure', Journal of Intellectual Capital, Vol. 4, No. 4, pp.543-58.

Brennan, N. (2001) 'Reporting intellectual capital in annual reports: evidence from Ireland', Accounting, Auditing and Accountability Journal, Vol. 14, No. 4, pp.423-36.

Brüggen, A., Vergauwen, P. and Dao, M. (2009) 'Determinants of intellectual capital disclosure: evidence from Australia', Management Decision, Vol. 47, No. 2, pp.233-245.

Chou, Y.C. (2016) 'Relationship among intellectual capital management', Organization Learning and Organization Performance. AUTHOR PLEASE SUPPLY PAGE RANGE.

Dias, A., Dias, A., Rodrigues, L.L., Rodrigues, L.L., Craig, R. and Craig, R. (2016) 'Global financial crisis and corporate social responsibility disclosure', Social Responsibility Journal, Vol. 12, No. 4, pp.654-671.

Dumay, J. (2016) 'A critical reflection on the future of intellectual capital: from reporting to disclosure', Journal of Intellectual Capital, Vol. 17, No. 1, pp.168-184.

Dumay, J., Guthrie, J. and Puntilla, P. (2015) 'IC and the public sector: a structured literature review', Journal of Intellectual Capital, Vol. 16, No. 2, pp.267-284.

Eng, L.L. and Mak, Y.T. (2003) 'Corporate governance and voluntary disclosure', Journal of Accounting and Public Policy, Vol. 22, No. 4, pp.325-345. AUTHOR PLEASE CITE THIS REFERENCE IN TEXT.

Gan, K., Saleh, Z., Abessi, M. and Huang, C.C. (2013) 'Intellectual capital disclosure in the context of corporate governance', International Journal of Learning and Intellectual Capital, Vol. 10, No. 1, pp.52-70.

Goh, P.C. and Lim, K.P. (2004) 'Disclosing intellectual capital in company annual reports: evidence from Malaysia', Journal of Intellectual Capital, Vol. 5, No. 3, pp.500-10.

Gray, D., Roos, G. and Rastas, T. (2004) 'What intangible resources do companies value, measure and report? A synthesis of UK and Finnish research', International Journal of Learning and Intellectual Capital, Vol. 1, No. 3, pp.242-261.

Guthrie, J. and Petty, R. (2000) 'Intellectual capital: Australian annual reporting practices', Journal of Intellectual Capital, Vol. 1, No. 3, pp.241-251.

Hope, O. (2003) 'Disclosure practices, enforcement of accounting standards and analysts' forecast accuracy: an international study', Journal of Accounting Research, Vol. 41, No. 2, pp.235272.

Ienciu, N.M. (2014) 'Intellectual capital disclosure from literature perspective', International Journal of Learning and Intellectual Capital, Vol. 11, No. 2, pp.166-183.

Kang, H., Cheng, M. and Gray, S.J. (2007) 'Corporate governance and board composition: diversity and independence of Australian boards', Corporate Governance: An International Review, Vol. 15, No. 2, pp.194-207.

Khan, M.W. J. (2015) 'Identifying the components and importance of intellectual capital in knowledge-intensive organizations', Browser Download This Paper. AUTHOR PLEASE SUPPLY PAGE RANGE.

Knudsen, J.S., Moon, J. and Slager, R. (2015) 'Government policies for corporate social responsibility in Europe: a comparative analysis of institutionalisation', Policy and Politics, Vol. 43, No. 1, pp.81-99.

Lins, K.V., Servaes, H. and Tamayo, A. (2017) 'Social capital, trust and firm performance: the value of corporate social responsibility during the financial crisis', The Journal of Finance. AUTHOR PLEASE SUPPLY PAGE RANGE.

Maaloul, A. and Zéghal, D. (2015) 'Financial statement informativeness and intellectual capital disclosure: an empirical analysis', Journal of Financial Reporting and Accounting, Vol. 13, No. 1, pp.66-90. 
Manolopoulou, E. and Tzelepis, D. (2014) 'Intellectual capital disclosure: the Greek case', International Journal of Learning and Intellectual Capital, Vol. 11, No. 1, pp.33-51.

Melloni, G. (2015) 'Intellectual capital disclosure in integrated reporting: an impression management analysis', Journal of Intellectual Capital, Vol. 16, No. 3, pp.661-680.

Muttakin, M.B., Khan, A. and Belal, A.R. (2015) 'Intellectual capital disclosures and corporate governance: an empirical examination', Advances in Accounting, Vol. 31, No. 2, pp.219-227.

Petty, R. and Guthrie, J. (2000) 'Intellectual capital literature review: measurement, reporting and management', Journal of Intellectual Capital, Vol. 1, No. 2, pp.155 - 176.

Simon, S.M.H. and Wong, K.S. (2001) 'A study of the relationship between corporate governance structures and the extent of voluntary disclosures', Journal of International Accounting, Auditing and Taxation, Vol. 10, No. 2, pp.139-156. AUTHOR PLEASE CITE THIS REFERENCE IN TEXT.

Strand, R., Freeman, E.R. and Hockerts, K. (2015) 'Corporate social responsibility and sustainability in Scandinavia: an overview', Journal of Business Ethics, Vol. 127, No. 1, pp.115 .

Thomsen, S. (2015) 'The Nordic corporate governance model', Management and Organization Review, Vol. 12, No. 1, pp.189-204.

Verbano, C. and Crema, M. (2016) 'Linking technology innovation strategy, intellectual capital and technology innovation performance in manufacturing SMEs', Technology Analysis and Strategic Management, Vol. 28, No. 5, pp.524-540.

Vidaver-Cohen, D. and Brønn, P.S. (2015) 'Reputation, responsibility and stakeholder support in Scandinavian firms: a comparative analysis', Journal of Business Ethics, Vol. 127, No. 1, pp.49-64. AUTHOR PLEASE CITE THIS REFERENCE IN TEXT.

White, H. (1980) 'A heteroskedasticity-consistent covariance matrix estimator and a direct test for heteroskedasticity', Econometrica, Vol. 48, No. 4, pp.817-838.

Xia, B.S. (2015) 'Innovation policies in managing growth for high-tech companies: a tactical synthesis of management insights', International Journal of Service Science, Management, Engineering and Technology, Vol. 6, No. 4, pp.33-42.

Xia, B.S. (2016) 'Strategic implications of voluntary disclosure and the application of the legitimacy theory', International Entrepreneurship, Vol. 1, No. 2, pp.109-120.

Xia, B.S. and De Beelde, I. (2016) 'Corporate governance and management incentives: evidence from the Scandinavian countries', Corporate governance. Work in Progress. AUTHOR PLEASE SUPPLY PAGE RANGE. 